\title{
HEPATOPULMONARY SYNDROME: UPDATE
}

\author{
Mohammed Osman El-Hassan Gadour ${ }^{1}$, Ephraim Ayobanji Ayoola ${ }^{2}$, Mohammad AM Ibnouf ${ }^{3}$, \\ Mohammed Saeed Al kalaefa ${ }^{1}$
}

\section{INTRODUCTION}

Although the pathophysiological mechanisms are not well -defined, the liverlung interaction has been well recognized since the nineteenth century ${ }^{1}$. It seems that the former has a crucial role in the control of the hemodynamics of the latter. The range of pulmonary changes associated with liver disease is very wide and is divided into structural e.g. the anatomical shunts, and functional e.g. intrapulmonary vasodilatation (IPVD). The consequences of these changes also have a wide range from pulmonary hypotension, gas exchange abnormality to portopulmonary hypertension. Severe hyoxemia associated with liver disease had been recognized decades ago.

The term hepatopulmonary syndrome (HPS) was suggested by Kennedy and Knudson in the late seventies of the last century ${ }^{2}$.

HPS is defined as a functional pulmonary insufficiency associated with liver disease in the absence of intrinsic cardiopulmonary pathology. It is a triad of liver disease and/or portal hypertension, severe hypoxemia and reversible IPVD. This IPVD is predominantly seen in the lower two thirds of the lungs

Patients with liver cirrhosis have hyperdynamic circulation and hyperventilation. In spite of this fact mild hypoxemia is seen in $70 \%$ of these patients ${ }^{3}$. The presence of ascites-which mechanically jeopardizes breathing-, hydrothorax and true pulmonary arterovenous shunt may contribute to this mild hypoxemia. IPVD, the structural hallmark of the HPS is the master of the low pulmonary vascular resistance and hence the reduced pulmonary arterial pressure characteristically observed in this disease.

The importance of this serious syndrome relates to the fact that a big group of doctors are not aware of this syndrome, despite being not uncommon among patients with liver disease. This leads to an under estimation of the problem and consequently to potential mismanagement of these patients.

1. Assoc. Prof. of Medicine. Department of Medicine. Omdurman Islamic University. Khartoum, Sudan.

2. Prof. of Medicine and Hepatology. USA.

3. Prof. of Surgery. Department of Surgery. Omdurman Islamic University. Khartoum, Sudan.

Correspondence;

Dr. M O EH Gadour. Ibn Sina Hospital.

Khartoum, Sudan.

Email: mgadour@hotmail.com
HPS is reported to affects around $10 \%$ of patients with liver disease and is present in $17.5 \%$ of cirrhotics, $13.3 \%$ of those with non-cirrhotic portal fibrosis, $10 \%$ with extrahepatic portal vein obstruction and in $20 \%$ of patients going for liver transplantation. Adult age groups, sex distribution and duration of symptoms were not different in patients with $\mathrm{HPS}^{4,5}$

It affects $2-4 \%$ of children with liver disease, with a range of $0.5 \%$ in those with portal vein thrombosis to $20 \%$ in biliary atresia and polysplenia syndrome. The syndrome is reported to affect children as young as 6 months of age ${ }^{6,7}$. HPS can affect patients with a wide spectrum of liver diseases including viral and non-viral hepatitis, granulomatous liver disease including sarcoidosis, hepatocellular carcinoma, inferior vena cava (posthepatic) obstruction, Budd-Chiari syndrome and is reported in patients with non cirrhotic portal hypertension and periportal fibrosis. HPS due to schistosomaisis was first reported in 1997. Pulmonary abnormalities and especially HPS are described in association with celiac disease and nodular regenerative hyperplasia $^{8-13}$.

\section{CLINICAL FEATURES}

Patients with HPS typically present with symptoms and signs of acute or chronic liver disease irrespective of its etiology. Clubbing, cynosis, spider naevi and esophageal varices are thought to be the best predictive clinical markers for the syndrome ${ }^{14}$. The characteristic clinical feature of the syndrome is dyspnea (platypnea) when the patient adopts the sitting or standing position which improves with recumbency. This is accompanied by reduction in oxygen saturation of hemoglobin (orthodeoxia). The appearance of platypnea and orthodeoxia- which are not pathognomonic of the disease- ${ }^{15,16}$ in the absence 
of cardiopulmonary disease should alert the treating team to the onset of the HPS. Dyspnea is seen in around $20 \%$ of patients with liver disease and is usually misattributed to cardiac causes or to the mechanical effect of ascites ${ }^{17}$.

Although HPS is reported to be more common in patients who have portal hypertension, no significant relationship was found between it and splenomegaly, ascites, edema, jaundice, oliguria, collateral veins or the etiology of the liver disease. ${ }^{18,14}$

Neither the nature nor the Childs-Pugh classification of the liver disease has an impact on the development of the HPS. In fact HPS may develop despite stable liver function. ${ }^{3}$.

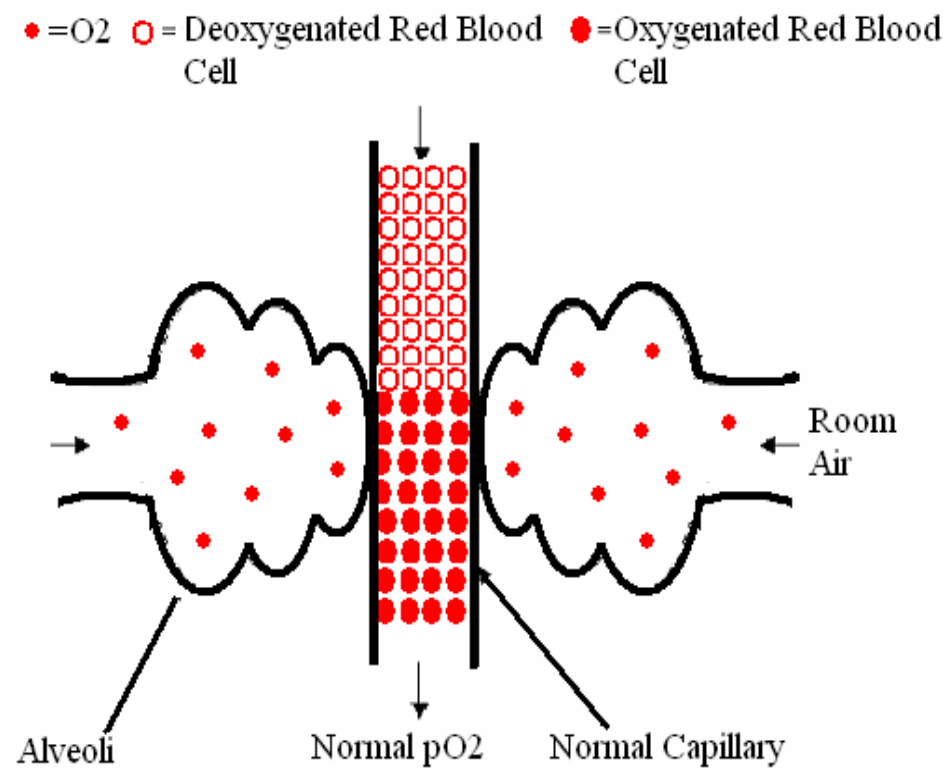

Fig 1. The $\mathrm{O} 2$ drive while breathing room air is enough to oxygenate $\mathrm{RBC}$ at the centre of a normal blood vessel (Adopted from Gadour et $\mathrm{al}^{3}$ )

Some patients with intrapulmonary vascular dilatations may not develop severe hypoxemia and is referred to as intrapulmonary vascular dilatation syndrome (IPVDS) or sub-clinical HPS. However, stressful conditions- which are associated with hyerdynamic circulation and short transit time for the blood in the pulmonary bed like exercise and pregnancy- may precipitate or uncover HPS in these patients. ${ }^{19}$

HPS is an indication for liver transplantation and at the same time it is an independent risk factor for morbidity and mortality in patients undergoing liver transplantation for other reasons ${ }^{3}$.

\section{MECHANISMS OF HYPOXEMIA}

Patients with liver cirrhosis commonly have hyperdynamic circulation with reduced peripheral resistance and systemic hypotension. The cardiac output may reach seven liters per minute. About $20 \%$ to $70 \%$ of this is conducted by the IPVD. The IPVD results from precapillary and capillary pulmonary vascular dilatations. These vessels may reach $500 \mu \mathrm{m}$ in diameter leading to functional right-to-left intrapulmonary shunting, though there is no true anatomic shunt. The compensatory tachycardia associated with systemic hypotension in these patients result in a short transit time for the blood in the lungs. When a normal person breathes room air, the $\mathrm{O}_{2}$ drivein the presence of an adequate transit time- is enough to oxygenate the red blood cells at the centre of the normal pulmonary vessels (Fig. 1). On the other hand the oxygen drive in patients with the HPS is short of oxygenating the red blood cells at the centre of the stream in the dilated capillaries (Fig.2). 


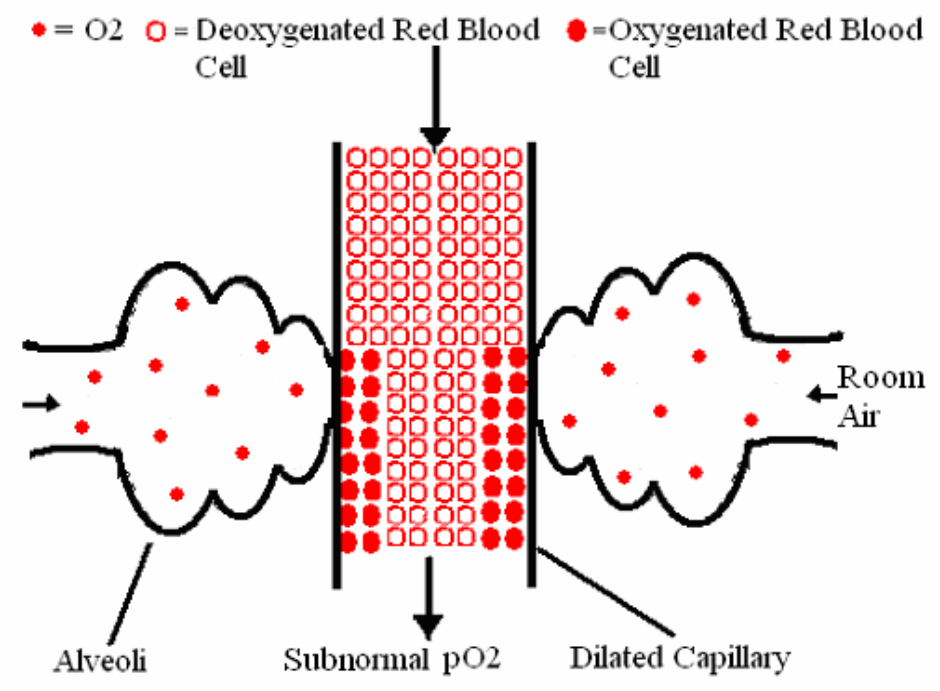

Fig 2. The $\mathrm{O} 2$ derive while breathing room air is not enough to oxygenate the RBCs at the centre of a dilated capillary

(Adopted from Gadour et al 3 )

This is further aggravated by the short transit time which does not provide the red blood cells with enough time in contact to the alveoli to acquire good amount of oxygen. As the vascular abnormalities predominate in the middle and lower lung fields, 'when such a patient is in the upright position a disproportionately larger amount of the blood in the pulmonary circulation preferentially- aided by gravity- flows to the dilated vessels in the hypoventilated lung bases. This further enhances ventilation-perfusion impairment leading to platypnea and orthodeoxia. Unlike what occurs in true anatomical shunts, supplemental oxygen provides enough driving pressure to overcome the relative diffusion defect in HPS (fig.3) ${ }^{3}$.

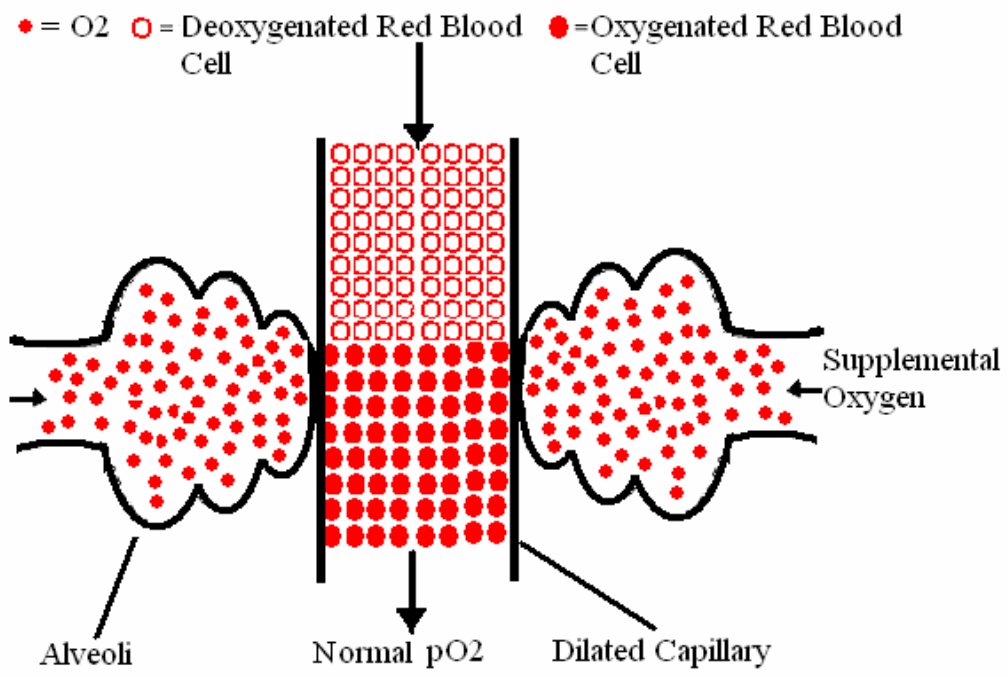

Fig 3. Supplemental $\mathrm{O} 2$ provides enough driving pressure to oxygenate the RBCs at the centre of a dilated vessel in HPS (Adopted from Gadour et $\mathrm{al}^{3}$ ) 
The existence of normal $\mathrm{O}_{2}$ tension in some patients who have IPVD shadows this dilatation leading to ventilation/perfusion impairment- as the sole cause for the severe hypoxemia seen in patients with HPS. Probably some other unknown factors play a role in that.

\section{PATHOGENESIS}

Beside patent airway and vascular bed a normal pulmonary vascular tone is mandatory for holding adequate ventilation / perfusion equation that maintain normal oxygenation. Disturbance of this tone either by elevation leading to portopulmonary hypertension or by reduction causing IPVD and HPS will lead to hypoxemia.

The cause of the IPVD which is the structural hall mark of the HPS is ill defined. The disturbed balance between the pulmonary vasodilators and vasoconstrictors is thought of as the corner stone in the pathogenesis of this syndrome. Three main theories were thought to be behind this vasodilatation. The first one is the presence of high level of circulating pulmonary vasodilators either due to their over production or under removal by the diseased liver or they may bypass the liver through the collaterals in patients with portal hypertension or in operation shunts ${ }^{20}$.

The second one is that the damaged liver leads to the inhibition of an unknown circulating vasoconstrictive substance or the reduction of other known pulmonary vasoconstrictors in the circulation as the principle cause for the dilatation. The third theory has been related to possible changes in the sensitivity or number of pulmonary receptors of these vasoactive factors. Some authors believe that activation of neurohumoral homoeostatic systems, like the renin-angiotensin-aldosterone system, the sympathetic nervous system and the hypothalamic/neuropituitary release of vasopressin may contribute significantly to the circulatory dysfunction seen in cirrhotics ${ }^{21-24}$.

Local vasoconstriction in hypo ventilated areas in the lung in order to divert the blood to well ventilated lung fields is an essential response to hypoxia. Impairment of this reaction may also contribute to the development of the HPS in these patients $^{25}$.

Postulations about the exact mediator/s of IPVD in the HPS are many. No single factor could explain the whole picture in all patients. However, a large number of possible substances in this category are under study. An ill defined mediator is still part of the on going research and treatment 3. Other possible mediators include carbon monoxide, tumor necrosis factor alpha, interleukins, endotheline-1(ET-1), prostaglandins, vasoactive intestinal peptide, calcitonin, glucagon, substance $\mathrm{P}$, atrial natriuretic factor, plateletactivating factor and endocannabinoids. Recently a lot of research work have focused especially on potent vasodilating substances, such as calcitonin gene-related peptide, adrenomedullin and nitric oxide $(\mathrm{NO})^{26}$ In addition, vascular endothelial growth factor (VEGF) is found to stimulate angiogenesis and the development of portosystemic collaterals. The blockade of this VEGF receptor-2 has been shown to inhibit this process $^{27}$.

NO has been proposed to be the key factor modulating the hemodynamic changes seen in HPS.

Investigations had shown high levels of exhaled NO in these patients which correlate significantly with disturbances in alveolo/arterial $\mathrm{O}_{2}$ gradient and ventilation/ perfusion equation. These disturbances and the equation return to normal after liver transplantation where exhaled NO level also become normal. Taken together this further reinforces the theory of the effect of NO in the pathogenesis of the syndrome ${ }^{28}$.

$\mathrm{NO}$ is a potent vasodilator that exerts a range of physiological and pathophysiological effects. It is a labile, highly reactive, diffusible gas that is synthesized mainly in the vascular endothelium from L-arginine by NO synthase. Three isoforms of NO have been identified: inducible NO, constitutive endothelial $\mathrm{NO}$, and neuronal $\mathrm{NO}^{29}$.

Endothelin 1, by increasing endothelial nitric oxide synthase activity significantly contributes to the increased levels of NO found in patients with HPS. ${ }^{30}$

This could be explained by the fact that 'there is an increased level of endothelin 1 in patients with portal hypertension possibly due to shear stress in endothelial cells caused by hyperkinetic circulation and also during hepatic injury. ${ }^{3}$ This is associated with increased expression of endothelin-1 receptors alpha and beta (ETRA \& ETRB) in the lung and hence the effect of ET-1 on NO production will be augmented resulting in wide spread IPVD, substantial disturbances in the ventilation / perfusion 
equation, widening of alveolar/arterial $\mathrm{O}_{2}$ gradient and leading to significant hypoxemia. ${ }^{31}$

\section{DIAGNOSIS}

Diagnosis of liver disease and exclusion of intrinsic cardiopulmonary disease has to be performed by the conventional methods. Hypoxemia and IPVD have to be proved. Determination of arterial oxygen saturation in the supine and upright position by using pulse oxymeter while the patients are breathing room air is a simple, non-invasive and useful screening test for identifying the majority of patients with $\mathrm{HPS}^{32}$,

Arterial $\mathrm{PO}_{2}<70 \mathrm{mmHg}$ and alveolar/arterial $\mathrm{O}_{2}$ gradient $>30 \mathrm{mmHg}$ and their sum, are the most valuable negative and positive predictive values in these patients ${ }^{14}$

It was reported that the positive predictive value for hepatopulmonary syndrome is about $30 \%$ for alveolar/arterial $\mathrm{O}_{2}$ gradient above $20 \mathrm{~mm} \mathrm{Hg}$ but $100 \%$ for arterial $\mathrm{PO}_{2}$ below $65 \mathrm{~mm} \mathrm{Hg}$ when the patient is breathing room air $^{34}$

\section{Routine investigations}

Complete blood count, liver function test, electrolytes and chest -x-ray may all be normal and are not helpful in the diagnosis of HPS. Determination of NO level is done by measuring its level in the exhaled air. This may represent a crude measure of gas exchange abnormalities in patients with liver disease.

The chest-X-ray may be normal or show the common findings seen in patients with liver disease. However, 'the characteristic appearance of increased bibasilar nodular or reticulonodular opacities representing dilated interstitial and pulmonary vascular bed in the clinical setting of liver dysfunction and hypoxemia highly suggests the presence of the $\mathrm{HP}^{3}$.

The finding of normal chest -X-ray and pulmonary functional tests in the presence of severe hypoxemia is suggestive of intrapulmonary vascular dilatation or arteriovenous shunt.

Unlike normal persons and patients with liver cirrhosis without severe hypoxemia; patients with HPS characteristically have radiological changes especially in the lower lung zones on $\mathrm{CT}^{35}$ Thorax high resolution CT may be helpful in the diagnosis of HPS by excluding pulmonary fibrosis and other interstitial lung diseases and demonstrating the dilated peripheral pulmonary vessels or increased pulmonary artery to bronchus ratios in patients with liver disease and hypoxemia ${ }^{36}$

Lung perfusion scans may be a useful test to exclude non-vascular causes of hypoxemia and it is helpful in semi-quantification of the severity of IPVD especially in follow up of patients with severe hypoxemia ${ }^{37}$.

\section{Assessment of gas exchange}

Severe hypoxemia $\left(\mathrm{PO}_{2}<60 \mathrm{mmHg}\right)$ with alveolar/arterial $\mathrm{O}_{2}$ gradient of $>15 \mathrm{mmHg}$ while breathing room air is the physiological hallmark for HPS. Because of hyperventilation, oxygen tension if $>65 \mathrm{mmHG}$ while the patient is breathing room air is not a good measure of pulmonary function in patients with HPS. Instead alveolar/arterial oxygen gradient is found to correlate well with lung dysfunction ${ }^{38}$. An increase in the alveolar/ arterial oxygen gradient by $>4 \mathrm{mmHg}$ when the patient adopts sitting or upright posture from recumbence is almost diagnostic of the HPS. Failure to improve $\mathrm{PO}_{2}$ with supplemental $100 \% \mathrm{O}_{2}$ inspiration usually indicate the presence of true arteriovenous shunts, sever type 1 or type 2 HPS.

\section{Special investigations}

Imaging techniques are mandatory for confirming the diagnosis, classification and grading the severity of IPVD. Commonly used ones include: Contrast-enhanced echocardiography, radiolabeled macro-aggregated albumin scanning and pulmonary arteriography.

Contrast-enhanced transoesophageal echocardiography (CTEE) although semiinvasive, is more sensitive in detecting IPVD in the early stages of hepatic insufficiency and has a better correlation with gas-exchange abnormalities than Contrast-enhanced TransThoracic Echocardiography CTTE ${ }^{39}$.

'Indocyanine green dye or agitated saline that provides a stream of micro-bubbles 60 to 90 microns in diameter are usually used in this test, as both of them normally opacify only the right heart chambers. They are trapped and filtered by the finer ( 8 microns) pulmonary capillary bed and therefore do not appear in the left side of the heart in normal lungs (Fig $1 \mathrm{~A}$ ). However, in the presence of an IPVD or intracardiac right-to-left shunt, these items opacify the left heart chambers (Fig 1 B) either by traversing the lung in the former condition or going directly through the shunt in the latter' ${ }^{3}$. In intracardiac right-to-left shunts these bubbles appear in the left heart in 3 heartbeats after they appear in the right heart while in IPVD and intrapulmonary shunts these bubbles appear in 4-6 heart beats. ${ }^{40}$ This timing is 
crucial for the differentiation between the two conditions, in addition the cause of the intracardiac left to right shunt is usually evident by the trans esophageal echo. However, it will not differentiate between IPVD and intrapulmonary shunts and will not quantitate the amount of the shunt. By detecting localized major IPVDs, CTEE will guide the decision for surgical or embolic intervention therapy.

Figure 1A Microbubbles in right heart chambers in contrast echocardiogram. (Courtesy of Yilmaz $\mathrm{S}^{11}$ )

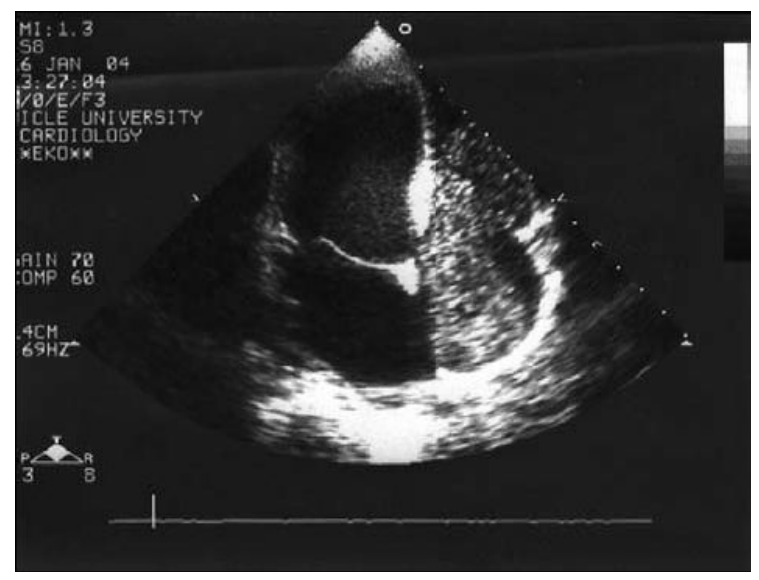

Figure 1B Microbubbles in left heart chambers in contrast echocardiogram. (Courtesy of Yilmaz $\mathrm{S}^{11}$ )

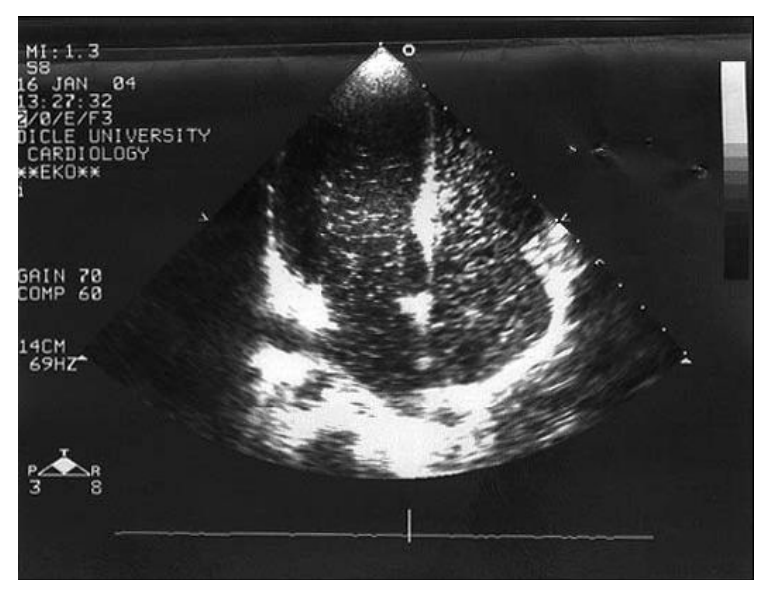

Macro aggregated albumin has large molecule exceeding $20-25$ microns in diameter which will not normally traverse the normal pulmonary capillary bed and when this albumin is radiolabeled with technetium $99 \mathrm{~m}$ a traceable compound is formed. The appearance of radioactivity over the kidneys or brain after injecting this substance intravenously indicates significant passage of these macro-aggregated particles through an intrapulmonary vasodilatation or an intracardiac shunt. The advantage of this test over the CTEE is its ability to quantify the magnitude of the IPVD or shunt. This is estimated by calculating the ratio of systemic to total body activity of the radionuclide ${ }^{41}$.

\section{Pulmonary arteriography}

This is an invasive procedure and hence it is reserved for selected cases especially those with poor response to $\mathrm{O}_{2}$. Depending on angiographic picture HPS is divided in to two types; type 1 which is further subdivided into a mild sub-type with finely diffuse, spidery infiltrates at the precapillary level close to gas-exchange units of the lung and this has a very good response to $100 \% \mathrm{O}_{2} ;$ and severe sub-type with more pronounced vascular dilatation and poor response to supplemented $\mathrm{O}_{2}$. Type 2 is characterized by localized spongy or blotchy angiographic appearance and poor response to $\mathrm{O}_{2}$. This type has good response to local spring-coil embolization or surgical resection therapy.

\section{TREATMENT}

Unfortunately there is no satisfactory medical treatment for the HPS. Finding a treatable underlying liver disease is the essential approach to the treatment of HPS.

Recovery of normal hepatic function either spontaneously or through treating the underling liver disease - if possible - results in resolution of the syndrome. On the other hand development of pulmonary hypertension in these patients reverses the IPVD and consequently leads to initial clinical improvement with normalization of oxygen saturation before the patient succumbs because of this new complication ${ }^{42}$.

Simple measures like putting the patient in recumbence position and supplying oxygen are the first line of therapy. These may ameliorate the patients' symptoms and are suitable means to buy time for those going for liver transplantation.

In attempting to resume the normal pulmonary vascular tone and reverse pulmonary vasodilatation several medical treatments to neutralize or inactivate circulating vasodilators were tried. Almitrine bismesylate, indomethacin, tamoxifen, somatostatin analogues, sympathomimetics, have been used in the treatment of HPS with disappointing results ${ }^{43-47}$. Plasma exchange, hemoperfusion and hemodialysis to remove an unknown vasodilator were attempted with unsatisfactory outcome ${ }^{17}$ Reduction of NO formation using agents like methylene blue or blockade of its action significantly increases arterial blood pressure and 
decreases plasma volume and sodium retention ${ }^{41}$, $48-50$

Trials to improve the circulation using vasoconstrictors like terlipressin combined with plasma expanders such as human albumin were done with controversial results. Endothelins, adenosine antagonists, long-acting vasoconstrictors, and antileukotriene drugs may prove effectiveness in preventing and treating HPS. $^{51}$

Transjugular Intrahepatic Portosystemic Shunt (TIPS) was thought of initially as treatment for HPS especially in patients with non-cirrhotic portal hypertension ${ }^{52}$. However recent data does not support that. Nevertheless, TIPS can be done safely to treat other complications of portal hypertension in patients with HPS and may improve levels of $\mathrm{PO}_{2}$ and be feasible, especially to gain time as temporal therapy for those waiting liver transplantation ${ }^{53}$. Lobular resection or spring-coil embolization therapy may temporary help some selected patients with type 2 HPS.

Because of the unsatisfactory results of medical therapy for the HPS, liver transplantation remains the gold standard treatment for the disease. Severe hypoxemia which initially was thought of as contraindication for the procedure is considered now as an indication for transplantation despite the pre-, intra- and postoperative morbidity and mortality risk. The perioperative mortality remains high (16-38\% within 1 year) and appears to be greatest in those with more advanced $\mathrm{HPS}^{54}$,

${ }^{55}$. Patients with HPS have increased postoperative mortality as well ${ }^{56}$. Sever hypoxemia (PO2 $<60 \mathrm{mmHg}$ ) and HPS are considered independent risk factors for surgery. The response to liver transplantation may not be immediate in fact some patients condition may deteriorate transiently postoperatively.

\section{PROGNOSIS}

The course of the disease is typically progressive. Although HPS is an independent risk factor for morbidity and mortality in patients with liver disease; the major morbidity and mortality in these patients are those of the liver disease and its complication. The mortality rate correlates with the pulmonary shunt volume and the degree of hypoxemia at room air ${ }^{57,58}$. The mortality of HPS in hospitalized patients is $41 \%$ after 2 years ${ }^{6}$. HPS may be complicated by pulmonary hypertension, embolic cerebral hemorrhage and postoperative hypoxemia. $^{59,60}$

Because of its significant morbidity and mortality in patients with liver disease and those who are going for transplantation before and after surgery, screening and staging the severity of HPS in patients going for liver transplantation was proposed recently ${ }^{61,62}$ and a scoring system was designed to predict the prognosis. However, this scoring system needs further verification in large population to assess its reliability. ${ }^{63}$

Interestingly HPS may show spontaneous clinical improvement if the patient develop pulmonary hypertension in the terminal stage of liver disease $^{64}$

\section{References}

1. Teramoto S, Matsuse T, Ouchi Y. Splenectomy-induced portal hypertension and pulmonary hypertension (letter). Ann Intern Med 1999; 131 (10):793.

2. Kennedy TC, Knudson R J. Exerciseaggravated hypoxemia and orthodeoxia in cirrhosis. Chest 1977; 72: 305-9.

3. Gadour M O EH, Ayoola EA Yousef A Z et al. Hepatopulmonary Syndrome .A review . The Saudi Journal of Gastroenterology 2001; 7: 85-94

4. Anand AC, Mukherjee D, Rao KS et al Hepatopulmonary syndrome : prevalence and clinical profile. Indian Journal of Gastroenterology 2001; 20(1):24-7.

5. Martinez-Palli G, Taura P, Balust J et al Liver transplantation in high-risk patients: hepatopulmonary syndrome and portopulmonary hypertension. Transplant Proc. 2005 Nov; 37(9):3861-4.

6. Mehri Najafi Sani, Hamid Reza Kianifar, Abdolrazagh Kianee et al Effect of oral garlic on arterial oxygen pressure in children with hepatopulmonary syndrome World J Gastroenterol 2006 April 21;12(15):2427-2431

7. Mc Diarmid SV. Treatment of end stage liver disease In: Walker WA, Durie PR, Hamilton JR, Walker-Smith SA, Watkins JB. Pediatric Gastrointestinal Disease, 3rd ed.Ontario: Bc Decker, 2000: 1264-1265.

8. Al-Moamary M, Altraif I. Hepatopulmonary syndrome associated with schistosomal liver disease. The Canadian Journal of Gastroenterology.July/August 1997; 11(5): 449450. 
9. Babbs C, Warners TW, Haboubi NY. Noncirrhotic portal hypertension with hypoxemia. Gut 1988; 29:129-131.

10. Ratti L, Pozzi M. The pulmonary involvement in portal hypertension: portopulmonary hypertension and hepatopulmonary syndrome. Gastroenterol Hepatol. 2006 Jan; 29(1):40-50.

11. Yilmaz S, Dursum M, Canoruc F et al A severe (type II) hepatopulmonary syndrome in a patient with idiopathic portal hypertension and treatment with paroxetine. Neth J Med. 2005 Dec; 63(11):448-52.

12. De BK, Sen S, Biswas PK, et al. Occurrence of hepatopulmonary syndrome in Budd-Chiari syndrome and the role of venous decompression. Gastroenterology 2002; 122: 897-903.

13. Cancado EL, Medeiros DM, Deguti MM et al Celiac disease associated with nodular regenerative hyperplasia, pulmonary abnormalities, and IgA anticardiolipin antibodies. J Clin Gastroenterol. 2006 Feb; 40(2):135-9.

14. Alizadeh AH, Fatemi SR, Mirzaee V et al. Clinical features of hepatopulmonary syndrome in cirrhotic patients. World J Gastroenterol. 2006 Mar 28; 12(12):1954-6.

15. Faller M, Kessler R, Chaouat $A$ et al. Platypnea-Orthodeoxia syndrome related to an aortic aneurysm combined with an aneurysm of the atrial septum. Chest 2000; 1 18:553-557.

16. Acharya SS, and Kartan R. A case of orthodeoxia caused by an atrial septal aneurysm. Chest 2000; 118:871-874.

17. Krowka M J, Dickson E R, Certese DA. Hepatopulmonary syndrome. Clinical observations and lack of therapeutic response to somatostatin analogue. Ches. 1993;

104: 515- 21.

18. Kaymakoglu S, Kahraman T, Kudat H, et al. Hepatopulmonary syndrome in

noncirrhotic portal hypertensive patients. Dig Dis Sci 2003; 48(3):556-60.

19 Sammour RN, Zuckerman E, Tov N et al. Pregnancy exacerbating hepatopulmonary syndrome. Obstet Gynecol. 2006 Feb; 107(2 Pt 2):455-7.

20. Fallon MB, Abrams GA, McGrath JW et al.
Common bile duct ligation in the rat: a model of intrapulmonary vasodilatation and hepatopulmonary syndrome. Am-J-Physiol. 1997; 272: $779-84$

21. Bernardi M, Trevisani F, Gasbarrini A et al. Hepatorenal disorders: role of the reninangiotensin-aldosterone system. Semin Liver Dis 1994; 14: 23-34

22. Arroyo V, Claria J, Salo J et al. Antidiuretic hormone and the pathogenesis of water retention in cirrhosis with ascites. Semin Liver Dis 1994; 14: $44-58$

23. Møller S, Henriksen JH. Neurohumoral fluid regulation in chronic liver disease. Scand J Clin Lab Invest 1998; 58: 361-372

24. Henriksen JH, Møller S, Ring-Larsen H et al. The sympathetic nervous system in liver disease. J Hepatol 1998; 29: 328-341.

25. Naeije R, Hallemans R, Mols $P$, et al. Hypoxic pulmonary vasoconstriction in liver cirrhosis. Chest 1981; 80: 570-574.

26. Lange and Stoller J K. The hepatopulmonary syndrome. Ann Intern Med. 1995;122 : 521-529.

27. Fernandez M, Mejias M, Angermayr B, Garcia-Pagan JC et al. Inhibition of VEGF receptor-2 decreases the development of hyperdynamic splanchnic circulation and portalsystemic collateral vessels in portal hypertensive rats. J Hepatol 2005; 43: 98-103

28. Rolla G, Heffler E, Bommarito L et alExhaled nitric oxide as a marker of diseases.Recenti Prog Med. 2005 Dec; 96(12):634-40.

29. Abrams GA, Trauner M, Nathanson MH. Nitric oxide and liver disease. Gastroenterologist 1995 Sep; 3 (3): 220-33.

30. Luo B, Abrams G, Fallon MB. Endothelin-1 in the rat bile duct ligation model of hepatopulmonary syndrome: correlation with pulmonary dysfunction. J Hepatol 1998; 29:571-8

31. Liu M, Tian D, Wang $\mathrm{T}$ et al. Correlation between pulmonary endothelin receptors and alveolar-arterial oxygen gradient in rats with hepatopulmonary syndrome. J Huazhong Univ Sci Technolog Med Sci. 2005; 25(5):494-6.

32. Peter Deibert, Hans-Peter Allgaier ,Loesch Stefanie et al. Hepatopulmonary syndrome in 
patients with chronic liver disease: role of pulse Oximetry ; Gastroenterology 2006, 6:15 -33.

33. Deibert P, Allgaier HP, Stefanie 1 et al. HPS in pts with CLD: role of pulse oximetry. BMC Gastroenterol 2006; 6(1): 15.

34. Schenk P, Fuhrman V, Madl Cet al. Hepatopulmonary syndrome: prevalence and predictive value of various cut offs for arterial oxygenation and their clinical consequences. Gut 2002; 51:853-9.

35. LeeKN, Lee HJ, Shin WW et al. Hypoxia and liver cirrhosis ( hepatopulmonary syndrome) in eight patients: comparison of the central and peripheral pulmonary vasculature. Radiology 1999; 211: 549-553.

36. Koksal D, Kacar S, Koksal AS et al Evaluation of intrapulmonary vascular dilatations with high-resolution computed thorax tomography in patients with hepatopulmonary syndrome. J Clin Gastroenterol. 2006 Jan; 40(1):77-83

37. Shijo H, Saaki H, Sakata H. et al. Okumura M. Reversibility of hepatopulmonary syndrome evidenced by serial pulmonary perfusion scan. Gastroenterol Jpn 1993, 28(1): 126-31.

38 Rodriguez-Roisin R, Agusti AG, Roca J. The hepatopulmonary syndrome:

new name, old complexities (Editorial). Thorax. 1992; 47: 897-902.

39. Rolla G, Brussino L, Colagrande $P$ et al. Exhaled nitric oxide and impaired oxygenation in cirrhotic patients before and after liver transplantation Ann Intern Med 1998; I29 (S): $375-8$

40 Ying-Wen Wang, Han-Chieh Lin. Recent Advances in Hepatopulmonary Syndrome. J Chin Med Assoc. 2005(68); 11: 500-505

41. Wolfe JD, Tashkin DP, Holly FE et al. Hypoxemia of cirrhosis : detection of abnormal small pulmonary vascular channels by a quantitative radionuclide method. Am J Med. 1977; 63: 746-54.

42. [45]. Andrivet P, Cadranel J, Housset B , Herigault R, Harf A, Adnot S. Mechanism of impaired arterial oxygenation in patients with liver cirrhosis and sever respiratory insufficiency. Effects of indomethacin. Chest 1993; 103: 500-7.
43. Meyers C, Low L, Kaufman L et al. Trendelenburg positioning and continuous lateral rotation improve oxygenation in hepatopulmonary syndrome after liver transplantation. Liver Transpl Surg 1998; 4(6):510-2

44. Caldwell SH, Jeffers JJ, Narula OS et al. Ancient remedies revisited: does Allium sativum [garlic] palliate the hepatopulmonary syndrome? J Clin Gastroenterol 1992; 15 : 248-50.

45. Andrivet $\mathrm{P}$, Cadranel J, Housset $\mathrm{B}$ et al. Mechanism of impaired arterial oxygenation in patients with liver cirrhosis and sever respiratory insufficiency. Effects of indomethacin. Chest 1993; 103: 500-7.

46. Krowka MJ, Cortese DA. Sever hypoxemia associated with liver disease: Mayo clinic experience and the experimental use of almitrine bismesylate. Mayo Clin Proc. 1987; 62: 164-73.

47. Soderman C, Juhlinl-Dannfelt A, Lagerstrand $\mathrm{L}$ et al. Ventilation-perfusion relationship and central heamodynamics in patients with cirrhosis Effects of somatostatin analogue .J Hepatol [Denemark] 1994; 21 [1]:52-7.

48. Hopkiins WE, Waggoner AD, Barzilai B. Frequency and significance of intrapulmonary right-to-left shunting in end-stage hepatic disease. Am J Cardiol 1992; 70: 516-9.

49 Nemec JJ, Davisen MB, Marwck TH et al. Detection and evaluation of intraoulmonary vascular shunts with contrast Doppler tranesophageal echocardiography. J Am Soc Echocardiogr 1991; 4: 79- 83.

50. Berthelot P, Walker JG, Sherlock S et al. Arterial changes in the lung in cirrhosis of the liver-lung spide nevi. N Engl J Med 1966; 274: 291-8.

51. Møller S; Henriksen JH. Pathogenesis and pathophysiology of hepatorenal syndrome--is there scope for prevention? Aliment Pharmacol Ther. 2004; 20 Suppl 3:31-41; discussion 42-3

52. Riegler JL, Lang KA, Johnson SP et al. Transjugular intrahepatic portosystemic shunt improves oxygenation in hepatopulmonary syndrome. Gastroenterology 1995 Sep; 109 [3]: 978-83

53. Martinez-Palli G, Drake BB, Garcia-Pagan JC et al Effect of transjugular intrahepatic 
portosystemic shunt on pulmonary gas exchange in patients with portal hypertension and hepatopulmonary syndrome. World J Gastroenterol 2005; 11(43): 6858-62.

54. Arguedas MR, Abrams GA, Krowka MJ et al. Prospective evaluation of outcomes and predictors of mortality in patients with hepatopulmonary syndrome undergoing liver transplantation. Hepatology 2003; 37: 192-197

55. Krowka MJ, Porayko MK, Plevak DJ et al Hepatopulmonary syndrome with progressive hypoxemia as an indication for liver transplantation: case reports and literature review. Mayo Clin Proc 1997; 72: 44-53.

56. Schiffer E, Majno P, Giostra E et al. HPS increases the postoperative mortality rate following liver transplantation: a prospective study in 90 patients. Am J transplant 2006 Jun;6(6) 1430-7.

57. Gschossmann JM, Essig M, Reichen $\mathrm{J}$ et al. The hepato-pulmonary syndrome--where do we stand in the year 2006? Z Gastroenterol. 2006 Mar; 44(3):249-56.

58. Schenk P, Schoniger-Hekele M, Fuhrmann V et al. Prognostic significance of the hepatopulmonary syndrome in patients with cirrhosis. Gastroenterology 2003; 125:1042-52.
59. Martinex-Palli G, Barbera JA, Taura P et al. Severe portopulmonary hypertension after liver transplantation in a patient with preexisting hepatopulmonary syndrome. J Hepatol 1993; 31:1075-9.

60. Abrams GA, Rose K, Fallon MB et al. Hepatopulmonary syndrome and venous emboli causing intracerebral hemorrhages after liver transplantation: a case report. Transplantation 1999; 68: 1809-11.

61. Mazzeo AT, Bottari G, Penna O et al. Significance of hypoxemia screening in candidates for liver transplantation: our experience. Transplant Proc. 2006; 38 (3): 793-4. 62. Herve P, Lebrec D, Brenot F et al. Pulmonary vascular disorders in portal hypertension. Eur Respir J 1998; 11: 1153-1166

63. Bottari G, Mazzeo ATand Santamaria LB. The importance of predicting the prognosis in patients with hepatopulmonary syndrome: a simple scoring system. Transplant Proc. 2006; 38(3): 795-7.

64. Umeda A, Tagawa M, Kohsaka $\mathrm{T}$ et al Hepatopulmonary syndrome can show spontaneous resolution: possible mechanism of portopulmonary hypertension overlap? Respirology. 2006; 11(1):120-3. 